\title{
Trouxe o faz de conta hoje? ¿Trajiste la fantasia hoy? Have you brought your make believe with you, today? Relato e performance didáctica.
}

\author{
Adriana Campos \\ Agradecimentos: Asssociação de Paralisia Cerebral de Coimbra (Projecto Estúdio), \\ Cândido Jacob e Graça Pereira Thomas
}

\section{Resumo}

Em 2018, um dos grupos de teatro da Associação de Paralisia Cerebral de Coimbra - o Projecto Estúdio, inaugura um rentável negócio que se propõe a rever o preço de um poeta e a utilidade de versos por medida. Em 2019, amplia a sua área de mercado, convida até os consumidores a experimentar um elixir invisível e investe numa pergunta (aparentemente) em miniatura: E o leitor, trouxe o faz de conta consigo hoje?

Palavras-Chave: faz de conta, elixir, inutilismo, arte, caixa de brinquedos.

\section{Resumen}

En 2018, uno de los grupos de teatro de la Associação de Paralisia Cerebral de Coimbra - Projecto Estúdio, abre un negocio rentable que tiene como objectivo revisar el precio de un poeta y la utilidade de los versos por medida. En 2019, expande su área de mercado, invita incluso a los consumidores a probar un elixir invisible e invierte en una pergunta (aparentemente) en miniatura: ¿ y el lector, trajo hoy una fantasia?

Palabras clave: fantasia, elixir, inutilidad, arte, caja de juquetes

\begin{abstract}
In 2018, Projecto Estúdio, one of the theatre groups at the Associação de Paralisia Cerebral the Coimbra, set up a highly profitable business which aims at reviewing the price of a poet and the usefulness of tailored verse. In 2019, Projecto Estúdio expanded its line of business, asking consumers to experiment an invisible elixir and it also invested in a (seemingly) miniature question: What about the readers, have they brought their make believe with them, today?
\end{abstract}

Keywords: make believe, elixir, uselessness, art, toy box. 
Caro leitor,

Permita-me uma advertência prévia! Este é um relato pouco convencional. Não espere ser conduzido maquinalmente por este conjunto de palavras. Não tenha a pretensão de ser embalado ao fim de um dia cansativo. Aliás, se conta com uma experiência com essas características, sugiro que pare imediatamente de ler este relato. Irá certamente, aborrecêlo e não vai ter utilidade!

Admita uma pergunta pronta: trouxe o faz de conta consigo, hoje?

É bem provável que não tenha dado conta do seu desaparecimento mas com o auxílio deste relato, terá as perguntas de que precisa.

Partilha certamente, da opinião que, "à medida que os filhos crescem, as casas [se] tornam (um pouco) mais ordenadas, aderem a uma rotina perfeita que durante anos não tiveram, numa respeitabilidade estável, segura de si" (MENDONÇA, 2015, p. 37). O que se passa das portas para dentro, não é muito diferente do que se passa da pele para dentro também.

Atrevo-me a adivinhar que não mexe numa caixa de brinquedos faz tempo ou que, dentro de portas (interiores), também há muito não deve saltar à corda, sorrir para uma nuvem que passa ou ficar com a boca escancarada com uma ideia (interior).

É que um exercício e outro, à medida que os filhos crescem, parecem perder a sua (in)utilidade. As histórias disparatadas, as peças órfãs dos jogos, as brincadeiras vão-se desfocando nas nossas vidas, assim como a arte, os símbolos ou a contemplação sem finalidade. Por isso, deixa-se a caixa dos brinquedos na infância.

Ciente deste problema que assola a humanidade, o Projecto Estúdio, um dos grupos de teatro da Associação de Paralisia Cerebral de Coimbra, depois da tentativa bem sucedida em 2018, de resgatar poemas dos objectos mais singelos

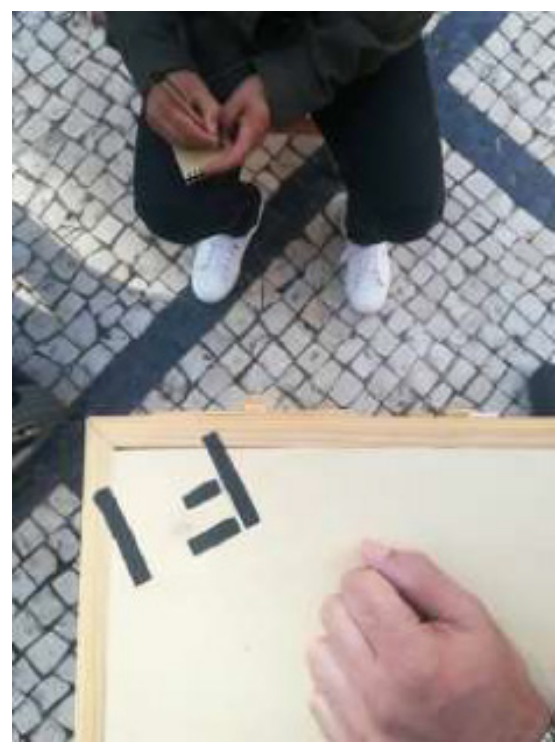

Imagem 1

Marca registada Loja [ambulante] de vender Fi. (porque uma janela "pode ser algo que está para além da definição do dicionário" (CRUZ, 2016, p.79), improvisa uma caixa de brinquedos e coloca-a no meio da rua (imagem 1 ).

Faça este exercício: imagine uma caixa de madeira em miniatura, com duas gavetas pequenas e duas outras maiores. Essa caixa está assente num módulo também de madeira e claramente, caixa e módulo, são pequenas demais para um qualquer adulto. No topo dessa caixa, em destaque, distingue-se a preto e em letras maiúsculas, a palavra FI. À frente dessa caixa ou pequeno armário, está uma cadeira de madeira (mais uma vez!) que o convoca, com as mesmas letras maiúsculas, a preto: FIQUE. Também a cadeira é pequena demais (imagem 2)!

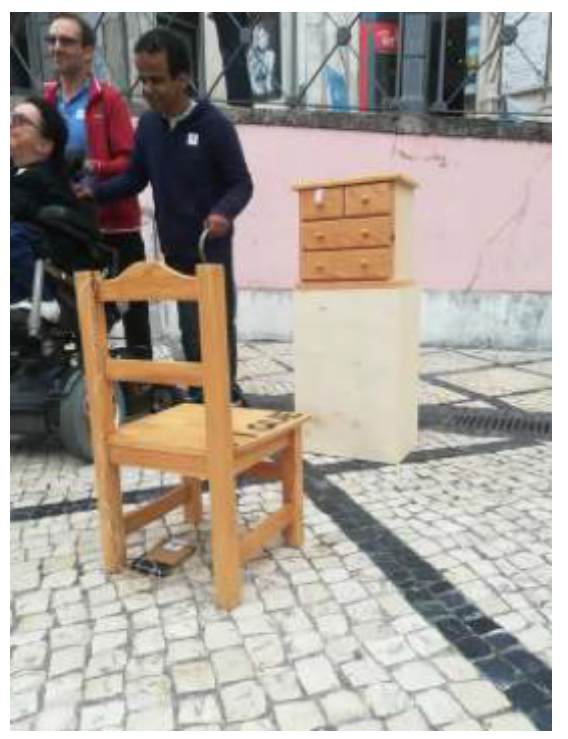

Imagem 2

Marca registada e cadeira Loja [ambulante] de vender $\mathrm{Fi}$

Importa-se de interromper a leitura e desenhar à margem de uma folha que tenha por perto, este objecto que acabou de ser descrito? Como uma caixa de brinquedos "principia uma estação de tréguas" (MENDONÇA, 2015, p. 37), talvez este exercício possa demorar mais do que imagina. Não faz mal, pode voltar atrás, se for necessário.

É bem provável que até agora, não tenha reparado no desaparecimento do faz de conta da sua vida mas com a ajuda deste relato pouco convencional, talvez obtenha as respostas perguntas de que precisa.

Regresse à caixa. Abra por favor, a primeira gaveta, a pequena! Imagine um álbum de família que se desenrola, como uma história de cordel, a preto e a branco.

Queira saber que, tal como na loja com a insígnia $\mathrm{FI}$, existe um produto desde o princípio dos tempos, concebido por uma família que guardou a sua poção em cavernas. Conta-se esta família terá construído templos para armazenar grandes quantidades de Fi e que esta receita chega a estar escondida secretamente em igrejas. Este produto transforma-se numa verdadeira herança para a humanidade!

Mas como uma caixa de brinquedos ganha outra dimensão se lhe atribuirmos um preço, aquele grupo de teatro 
transforma o tal pequeno armário numa loja ambulante de vender um produto altamente rentável, de marca registada, estudado e adaptado às exigências de mercado e capaz de apresentar resultados imediatos na sua vida.

Abra por favor, a segunda gaveta: repare no fundo preto e em todos os objectos que a branco, sobressaem. Imagine um laboratório em miniatura, todo aprumado, com os utensílios alinhados, uma espécie de gabinete de curiosidades mas com objectos brancos, definidos, rectos, como manda a contemporaneidade de um qualquer laboratório (imagem 3). Imagine todos os objectos fixos, à excepção de um que o desafia...

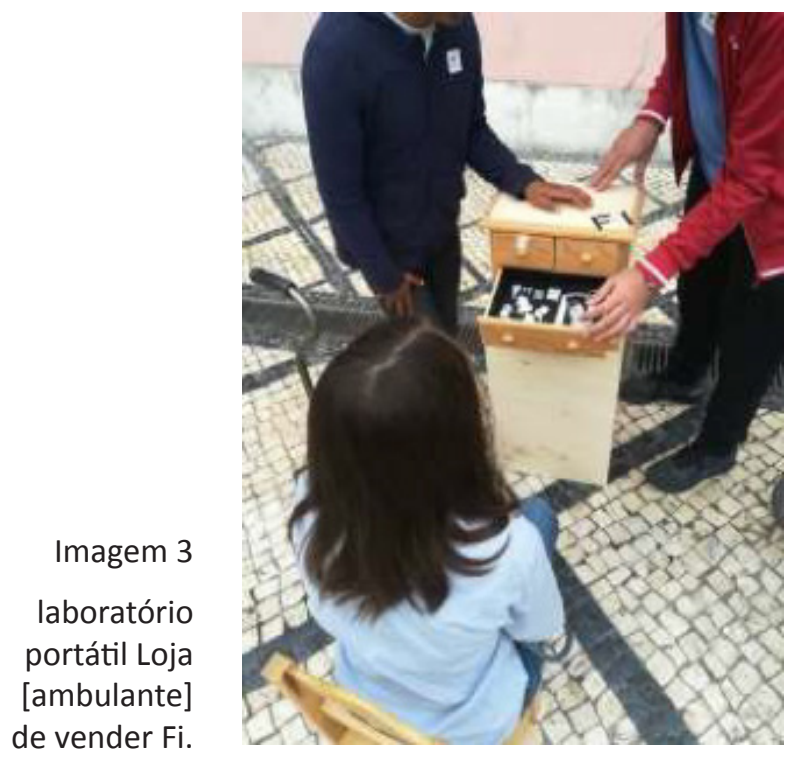

Finja por último, que um frasco branco minúsculo, com uma rolha branca, de cortiça, igualmente pequena e um elixir transparente a chamar por si (faz de conta!). Sem sair deste relato pouco convencional, abra o frasco, coloque umas gotas desse elixir invisível (faz de conta!) sob os pulsos como se fosse um perfume e deixe-se sentir borboletas na barriga (faz de conta!)! Sabe que basta um Fi por dia para activar a sua curiosidade, refrescar as perguntas que existem dentro de si e nalguns casos, convocá-lo a ir ao teatro?

A Loja [ambulante] de vender Fi foi criada especialmente, a pensar em si!

Abra agora, a gaveta mais difícil. Esta gaveta é tão grande quanto a anterior mas parece estar perra ou ter algo a encravá-la. Dentro dela, imagine o mesmo fundo preto da gaveta anterior, uma gambiarra de luzes muito pequenas suspensas no topo e cá em baixo, a preto e branco, prédios, casas, torres e uma publicidade gigante num dos topos dos edifícios: FI. Ao fundo desses prédios, várias personagens reais e irreais.

O que imagina ter visto à sua frente?

Aproveite as margens da folha que utilizou há pouco, e tome nota de um título que resuma esta última gaveta (imagem 4).

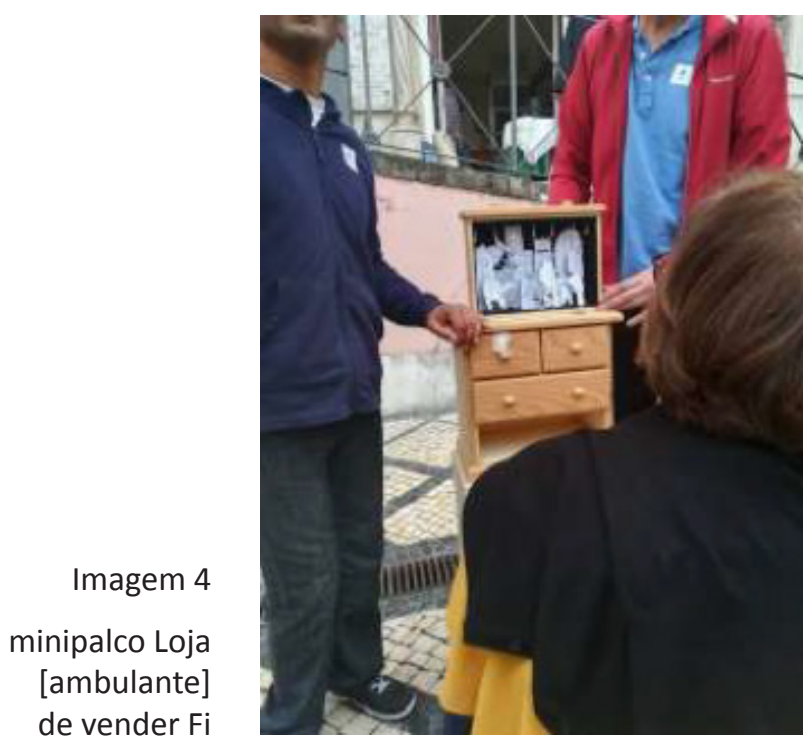

Na loja, mais do que o que foi dito, vêem-se de facto, pessoas com borboletas na barriga, elixires transparentes parecem cheirar a limão, e irrompem sorrisos sem palavras (imagem 5). Ouvem-se espantos, comentários descomprometidos e histórias inesperadas; pessoas fingem acreditar na história que se conta, fingem comprovar a eficácia desse elixir milagroso e fingem ver palcos em miniatura.

Imagem 5

transeuntes Loja

[ambulante]

de vender $\mathrm{Fi}$

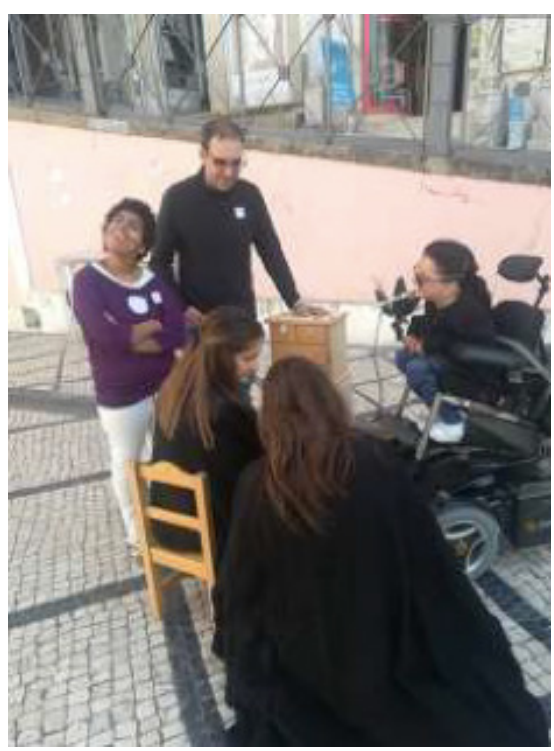

Não pode este relato medir a inutilidade das suas notas mas como se comprova, consumidores e leitores, são capazes de acreditar inutilmente que fingir ou fazer de conta podem ser a substância da nossa vida. Por isso mesmo, é condecorado, neste instante, por este relato pouco convencional, como inuFilista.

Pode dentro de uma caixa como aquela(s), estar a arte de fazer tempo?

Pode uma caixa como aquela(s), servir para alguma coisa? 
O que pode afinal, uma caixa como aquela(s)?

Num apelo claro a que transeuntes/espectadores interrompam a sua vida por instantes, o Projecto Estúdio tem gasto os seus dias a inventar fórmulas e antídotos que, em vez de respostas, repete perguntas. Investe por isso, em negócios que existem desde o princípio dos tempos e que definem a própria humanidade.

À semelhança do que aconteceu em 2018, na Loja [temporária] de vender Poetas, neste novo espaço comercial, propõe-se um jogo de faz de conta e a pretexto de um pequeno frasco vazio, convida-se a voltar a esse exercício de infância: brincar (imagem 6).

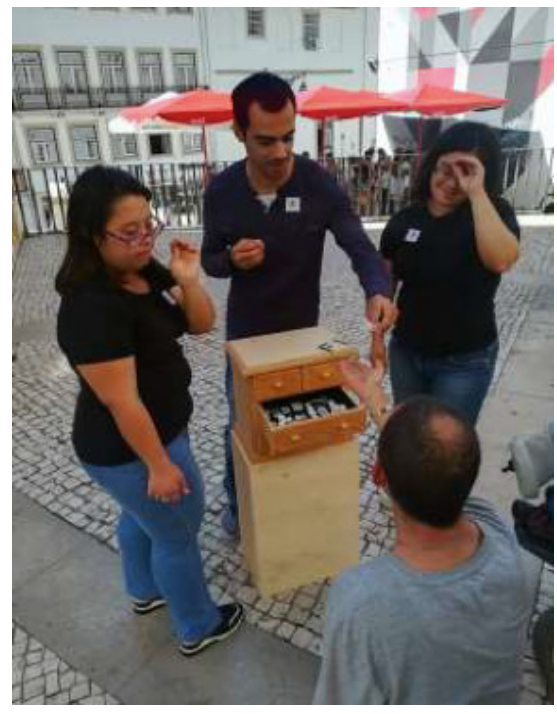

Imagem 6

uma das equipas

especializadas

Loja [ambulante]

de vender $\mathrm{Fi}$

E por instantes, nesse tempo sem definição, volta-se às peças soltas, às gargalhadas debaixo das árvores, aos joelhos esfolados...

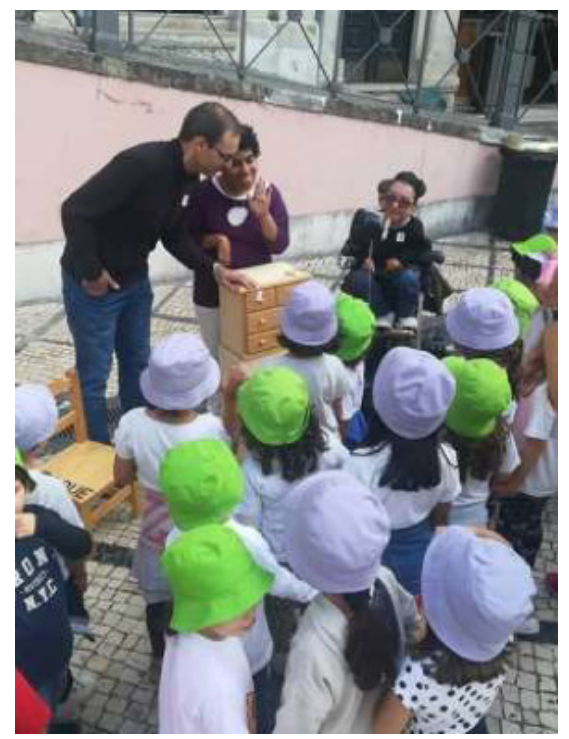

Imagem 7

convidados do tamanho da Loja [ambulante] de vender $\mathrm{Fi}$

A arte e o teatro em particular, são muitas vezes equiparados a esse exercício de fazer de conta que tal como este relato, não nos embala, mas exige de nós e das nossas memórias, uma presença viva, construída de forma única, em cada representação. O tempo fica suspenso e somos convidados a mergulhar numa ficção.

Essa grande caixa preta, a que se pode voltar mesmo que os filhos cresçam, não serve efectivamente para nada. Abre as cortinas ao espanto, inquieta-nos o coro cabeludo, faznos entrar em realidades que só existem porque decidimos acreditar (como na infância!).

Nessa caixa - seja um pequeno armário ou uma grande caixa preta de um auditório nacional, "está a arte de fazer tempo, de perdê-lo para que se torne mais nosso, permitindo a imaginação, o sentido lúdico e a alegria ...

A caixa de brinquedos não serve para nada, e por isso dános razões para viver!” (MENDONÇA, 2015, p. 37).

Mesmo que os filhos cresçam! (imagem 7)

\section{Bibliografia}

CRUZ, A. (2016). Vamos comprar um poeta. 3ạ edição, Editorial Caminho, SA. Alfragide.

MENDONÇA. J.T. (2015). Que coisa são as nuvens. 1ạ edição, Expresso (Impresa Publishing). Paço de Arcos. 